\title{
EUTOMIA
}

Revista de Literatura e Linguística

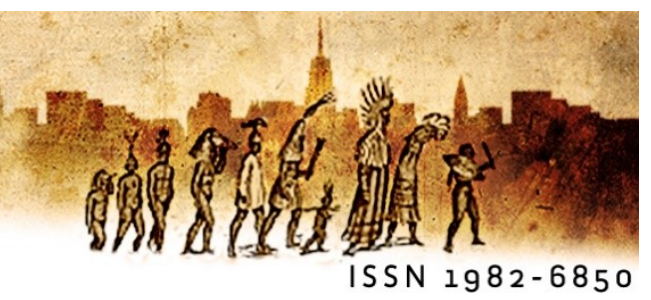

\section{Direitos de Autor \\ 1917 - Grandes transformações no mundo e no Brasil}

\author{
Copyright \\ 1917- Big transformations in the world and in Brazil
}

Mário Sergio Medeiros ${ }^{\mathrm{i}}$

\begin{abstract}
Resumo: O autor, ex-diretor da SBAT, narra como evoluiu a Lei de Direitos de Autor ao longo dos anos, quando o mundo passava por grandes transformações, como a Primeira Guerra Mundial e a Revolução Russa.

Palavras-chave: Direitos de Autor; Chiquinha Gonzaga; Primeira Guerra.

Abstract: The author, former director of SBAT, narrates how the copyright Law evolved throughout the years, when the world was undergoing big transformations like the First World War and the Russian Revolution.

Keywords: Copyright; Chiquinha Gonzaga; World War.
\end{abstract}

No ano de 1900, em plena virada de mais um século, no verão carioca, a música que sempre habitou os nossos sentimentos, ecoava pelas ruas do Rio. Era uma multidão de pessoas que se fantasiava, colocava máscaras, dançava e cantava as marchinhas que cresciam para o batuque fazendo uma zoeira só de alegria. Era carnaval.

Virar mais um século aumentava a esperança de que com a República consolidada, seríamos um país mais livre. O simbolismo do século que se inicia estava no imaginário coletivo. Passava de boca em boca. Estava nas rodas de conversa. Nos almoços de domingo. Nos palácios, nas casas, nas ruas, nos cortiços, na cidade e na favela que começava a se formar nos morros cariocas. Da elite ao povo negro, todos brindavam ao alvorecer de uma nova era.

"Ô abre alas que eu quero passar", era a música talvez mais cantada nos festejos populares, no aglomerado de pessoas que comungavam da mesma alegria. 
Essa música era de Francisca Gonzaga, mais conhecida como Chiquinha. Esse sem dúvida foi o hino que provocava o povo às ruas, derramando sem pudor e sem pecado, os prazeres da carne. Aliás de onde se originou a palavra carnaval, que era comemorado antes da quaresma. Na quaresma eram contados 40 dias antes da Semana Santa, onde a igreja sugeria - para não dizer impunha - um jejum coletivo aos católicos com abstinências de toda ordem: carne-pecado, música-pecado, sexopecado. Lógico que as práticas por debaixo dos panos eram outras, mas não dizia-se que fazia.

Nada mais do que justo, que 40 dias antes as pessoas se acabassem, bebessem e dançassem até cair no pecado. Chiquinha Gonzaga era uma mulher que esteve sempre à frente de seu tempo. Ousada, desafiou a nobreza e a sociedade carioca, desmanchando um casamento infeliz, onde não havia amor, só viver sob jugo de seu marido militar. E isso ela não podia suportar. Chiquinha era filha de um também militar com uma negra, o que lhe dava a aparência mulata. Desde cedo gostava do piano e foi nele que se entregou totalmente para compor suas valsas, polkas, até que descobriu a música de origem africana.

Chiquinha, em vez de frequentar os saraus da corte, percorria os terreiros onde os negros se encontravam para forjar seu batuque e dançavam ao som do Lundu. Que ritmo quente aquele, que dança sensual! Não dava outra, foi pesquisando e aprimorando a sua música que compôs lindas canções e foi junto com Ernesto Nazaré que criou o chorinho.

Uma vez separada do marido, Chiquinha segue livre para compor e continuar pesquisando a música. Ela gostava também muito de namorar e viajar. Mas o que esse detalhe tem a ver com essa prosa? Nada, só para dizer que foi numa viagem à Europa que ela sentada num café ouviu suas músicas sendo tocadas ao piano.

Chiquinha separada, longe dos filhos, morando sozinha tinha que sobreviver. Ela dava aulas de piano para jovens músicos e se apaixonou por um de seus alunos bem mais novo do que ela. Mais um escândalo em sua vida? Sem dúvida. Ela começou a compor música para o teatro da época e recebia dos produtores pela sua obra, nada. Naturalmente eles pagavam os jantares dela nos restaurantes onde sempre acabava dando uma canja. Era assim que sobrevivia. 
Chiquinha costumava deixar suas partituras para serem vendidas numa famosa casa de pianos na Rua do Ouvidor, no Rio de Janeiro. E o dono vendia as reproduções dessas partituras. Várias dessas foram parar na Europa e não só mais a Alemanha, mas Itália, França, Portugal, todos os países tocavam Chiquinha. E ela não recebia um centavo por isso.

Na sua volta ao Brasil reúne uma séria de jornalistas, autores e compositores e relata que o presenciou na sua viagem pela Europa. Alguma coisa precisava ser feita. Na Europa já haviam algumas Leis do começo do século XIX, onde alguns Estados já haviam promulgado suas leis sobre direito de autor, sendo somente no final do mesmo século que vários Estados assinaram o primeiro acordo multilateral sobre o assunto: a Convenção de Berna de 1886, da qual o Brasil se tornou signatário a partir de 1922.

Vale dizer que o texto do também chamado Convênio de Berna para a Proteção das Obras Literárias e Artísticas em vigor hoje em dia é aquele da sua última revisão, realizada em 1971.

Em 1952, foi aprovado outro instrumento básico sobre direito de autor, a Convenção Universal sobre Direito de Autor, realizada em Genebra, com a adesão dos Estados Unidos e da extinta União Soviética.

Assim, figuram como instrumentos internacionais básicos sobre direito de autor a Convenção de Berna e a Convenção Universal, sendo que os direitos conexos de autor são regulados pela Convenção de Roma de 1961.

Chiquinha sabedora dessas informações propôs, então, a criação da primeira sociedade brasileira para atuar em defesa do Direito Autoral. E em 27 de setembro de 1917, na seda da ABI - Associação Brasileira de Imprensa, foi criada a SBAT Sociedade Brasileira de Autores Teatrais que reunia os autores e compositores numa sociedade de gestão coletiva e escolhido o seu primeiro presidente, João do Rio, famoso por suas crônicas sobre o Rio de Janeiro em jornal carioca.

Estava criada uma sociedade de autores que defenderia os direitos de representação de seus associados. O Teatro é considerado no mundo todo como os Grandes Direitos e a música os Pequenos Direitos. Mas o primeiro registro com relação a proteção dos direitos autorais no Brasil ocorreu em 1827. Na época, a promulgação da lei Imperial - ao instituir os cursos jurídicos de São Paulo e Olinda - 
estabeleceu no seu artigo $1^{\circ}$ o privilégio pelo período de 10 anos sobre todas as obras textuais criadas pelos professores.

Em 1830, a penalização pelo desrespeito do direito do autor veio no art. 261 do Código Criminal, onde estavam expressos os direitos exclusivos do cidadão de imprimir, gravar, litografar ou introduzir qualquer escrito ou estampa, por ele próprio feito, enquanto viver e para seus herdeiros por 10 anos após sua morte.

Entretanto, a primeira lei de fato sobre os direitos autorais surgiu apenas em 1898. A Lei Medeiros e Albuquerque consolidou a proteção legal do direito autoral no país. Ela foi responsável por estabelecer o direito no âmbito da propriedade literária, científica e artística.

Apesar de o Código Civil de 1916 ter complementado a Lei, com o passar dos anos os dispositivos sobre o direito do autor começaram a entrar em conflito com a evolução dos meios de comunicação e reprodução de sons e imagem. A solução foi publicar mais leis e decretos para solucionar tais conflitos. Ao final, a matéria legal era tanta que precisou ser unificada em uma única lei: a Lei n 5.988 de 1973.

A Lei foi a referência brasileira sobre o tema, até que foi promulgada a Constituição de 1988. A partir de então, os direitos autorais foram garantidos pelo Inciso XXVII no art. $5^{\circ}$ da Constituição Federal.

Hoje, além de garantido pelo Inciso XXVII, o direito autoral é regulado, em específico, pela Lei de Direitos Autorais no 9.610 ("LDA"), editada em 1998. Apesar de não ser considerada como inovadora no aspecto jurídico em comparação à lei anterior, a LDA surgiu como importante instrumento para abarcar as necessidades dos novos padrões sociais.

Existem correntes que afirmam que surge o direito de autor junto a invenção da imprensa na Europa no século XV, criada por Gutemberg. Entretanto, é sabido que muito antes da invenção da imprensa na Europa, a China e a Coréia já contavam com técnicas de impressão e não se pode esquecer que já havia noções de propriedade sobre os trabalhos intelectuais na antiguidade, sobretudo na Roma antiga.

Por tais motivos, parece certo afirmar que as bases do Direito de Autor foram consagradas ainda na época das civilizações clássicas. Na Grécia e na Roma antigas, 
berços da civilização ocidental, surgiram grandes pensadores que lançaram as bases de muitas ciências modernas, entre elas, o Direito.

A primeira lei que garantia a proteção do direito individual sobre uma obra impressa foi realizada na Inglaterra em 10 de abril de 1710, conhecida como lei da Rainha Ana ou Copyright Act, ou seja, Ato do Direito de Cópia. Esta lei destinou-se a proteger os editores contra a reprodução ilegal e sem autorização de seus impressos. Contudo, ainda não protegia os verdadeiros autores das produções intelectuais, configurando apenas como um privilégio de impressão.

Séculos seguintes, durante a Revolução Francesa, foi aprovado um decreto sobre direito de autor em 1791, que sancionou o direito de execução e representação, e outro de 1793 que garantiu ao autor o direito exclusivo de reprodução.

Conforme a LDA de 1998, é entendido que o direito autoral é separado em direitos morais e direitos patrimoniais. Os Direitos Morais são vinculados à personalidade do autor e são inalienáveis - ou seja, somente o autor tem permissão de alterar ou realizar qualquer modificação a sua obra. Enquanto o Patrimonial diz respeito à utilização e controle de reprodução - no caso mais amplo, ao uso econômico da obra - e pode ser vinculado aos herdeiros.

Mas voltando a 1917, ano importante porque estava ocorrendo na Europa a Primeira Grande Guerra Mundial. Recém-industrializada e sofrendo com a Guerra, a Rússia tinha uma grande massa de operários e camponeses trabalhando muito e ganhando pouco. Além disso, o governo absolutista do czar Nicolau II desagradava o povo que queria uma liderança menos opressiva e mais democrática. E por absoluta insatisfação da população com os rumos da participação russa na guerra, veio a derrubada do Czar. A soma dos fatores levou a manifestações populares que transformaram a Rússia em União Soviética, o primeiro país comunista do mundo. Estava completa o que chamamos de Revolução Russa de 1917.

O Brasil não participou dessa guerra. Por aqui os ares Europeus ainda se faziam presentes desde a virada do século. E isso se traduzia nas Artes e na Arquitetura. A influência francesa da Belle Époque, era vista nas roupas, nas atitudes, nos prédios e objetos em Art Nouveau, na arquitetura eclética dos grandes prédios, em contraste 
com uma população cada vez mais pobre, ocupando os morros da cidade e com o surgimento das primeiras favelas.

Desde o início do século $X X$, o planejamento urbano da cidade do Rio de Janeiro, herdado do período colonial e do Império, não condizia mais com a condição de capital e centro das atividades econômicas. Além disso, a cidade sofria com sérios problemas de saúde pública. Doenças como a varíola, a peste bubônica e a febre amarela assolavam a população e preocupavam as autoridades. No intuito de modernizar a cidade e controlar tais epidemias, o presidente Rodrigues Alves iniciou uma série de reformas urbanas e sanitárias que mudaram a geografia da cidade e o cotidiano de sua população. As mudanças arquitetônicas da cidade ficaram a cargo do engenheiro Pereira Passos, nomeado prefeito do Distrito Federal. Ruas foram alargadas, cortiços foram destruídos e a população pobre foi removida de suas antigas moradias. Ao médico Oswaldo Cruz, que assumiu a Diretoria Geral de Saúde Pública em 1903, coube a campanha de saneamento da cidade, que visava erradicar a febre amarela, a peste bubônica e a varíola. Com este intuito, em junho de 1904, o governo fez uma proposta de lei que tornava obrigatória a vacinação da população.

Há quem diga que essas mudanças foram propositais, necessárias, mas havia outra intenção por trás de tudo. A ideia de modernização da cidade era uma constante, mas era uma grande oportunidade de uma limpeza na cidade do Rio de janeiro, uma limpeza também étnica. Os pobres, na sua grande maioria negros, viviam amontoados em casarões transformados em "curtiços", habitados por muitas famílias e sem muitas condições de higiene. O higienismo é uma doutrina que nasceu na primeira metade do século XIX, quando os governantes começaram a dar maior atenção à saúde e à moral dos habitantes das cidades. Considerava-se que a doença era um fenômeno social que abarcava todos os aspectos da vida humana. A necessidade de se manterem determinadas condições de salubridade no ambiente da cidade mediante a instalação de adução e tratamento da água, esgotos, iluminação nas ruas, e assim poder controlar as epidemias foram dando forma a esta corrente.

Como podemos ver foi um começo de século conturbado. O mundo estava mudando. A Revolução Industrial começada no século XVIII e se estendendo pelo século XIX, teve a Inglaterra como precursora devido a diversos fatores, entre eles: possuir uma rica burguesia, o fato do país possuir a mais importante zona de livre 
comércio da Europa, o êxodo rural e a localização privilegiada junto ao mar o que facilitava a exportação.

Como muitos empresários ambicionavam lucrar mais, o operário era explorado sendo forçado a trabalhar até 15 horas por dia em troca de um salário baixo. Além disso, mulheres e crianças também eram obrigadas a trabalhar para sustentarem suas famílias.

Em 1917 também, Anita Malfatti, Artista Plástica recém chegada da Europa, resolveu promover sua segunda exposição na cidade de São Paulo. Mas após a crítica de Monteiro Lobato, publicada em O Estado de São Paulo, edição da tarde, em 20 de dezembro de 1917, com o título de A propósito da exposição Malfatti, as telas vendidas foram devolvidas, algumas quase foram destruídas a bengaladas. Um verdadeiro massacre a quem veio a ser, junto com Oswald e Mario de Andrade, a precursora do modernismo no Brasil.

Tudo isso para dizer que, diante de tanta coisa acontecendo no Brasil e no mundo nesse início do século XX, sem dúvida, a entrada da SBAT no cenário cultural brasileiro trouxe aos autores e compositores um respeito por parte dos produtores e editores. As suas obras passaram a ser mais bem cuidadas e conhecidas mundialmente, protegidas pela sociedade a qual haviam fundado. E Chiquinha Gonzaga, aos 88 anos de idade, morre em 1935 no Rio de Janeiro. A sua ousadia e determinação nos deixou um legado que dura até hoje. Aos 102 anos de idade a SBAT protege o Direito de Autor - a propriedade intelectual - e mantém no seu acervo 40.000 obras devidamente catalogadas. Esse acervo encontra-se sob a guarda da Biblioteca Nacional.

Lá podemos encontrar a história do Teatro brasileiro do século $X X$. $E$, naturalmente lá também, está uma parte da história do Brasil contada através do Teatro. A SBAT é a Casa do Autor brasileiro. Por lá já habitaram Francisca Gonzaga, João do Rio, Bastos Tigre, Luiz Peixoto, Raul Pederneiras, Oduvaldo Vianna, Viriato Correa, Gastão Tojeiro, Silveira Sampaio, Raimundo Magalhães Junior, Oswald de Andrade, Mario de Andrade, Menotti del Picchia, Nelson Rodrigues, Jorge Amado, Dias Gomes, Janete Clair, Bráulio Pedroso, Gianfrancesco Guarnieri, Jorge Andrade, Vianinha, Consuelo de Castro, Mauro Rasi, Ariano Suassuna, Plínio Marcos, Ferreira 
Gullar, Augusto Boal e tantos e tantos outros que fizeram e ainda fazem a alegria do povo brasileiro. A SBAT é um patrimônio cultural do Brasil.

1917, ano da Revolução Russa e nascimento da SBAT. A Revolução acabou mas a SBAT continua, na luta pelo Direito de Autor. Evoé!

' Arte Educador, Roteirista, Dramaturgo e Diretor. É membro da SBAT - Sociedade Brasileira de Autores desde 1980, com diversos textos registrados.

E-mail: mariosImedeiros@gmail.com 